\title{
Improved rapid molecular diagnosis of multidrug-resistant tuberculosis using a new reverse hybridization assay, REBA MTB-MDR
}

\section{Correspondence \\ Hyeyoung Lee \\ hyelee@yonsei.ac.kr}

Received 16 March 2011

Accepted 16 May 2011
Hyeeun Bang, ${ }^{1}$ Sangjung Park, ${ }^{1}$ Joohwan Hwang, ${ }^{1}$ Hyunwoo Jin, ${ }^{1}$ Eunjin Cho, ${ }^{2}$ Dae Yoon Kim, ${ }^{3}$ Taeksun Song, ${ }^{2}$ Isdore Chola Shamputa, ${ }^{4}$ Laura E. Via, ${ }^{4}$ Clifton E. Barry, III, ${ }^{4}$ Sang-Nae $\mathrm{Cho}^{5}$ and Hyeyoung Lee ${ }^{1}$

\author{
${ }^{1}$ Department of Biomedical Laboratory Science, College of Health Sciences, Yonsei University, \\ Wonju 220-710, Republic of Korea \\ ${ }^{2}$ International Tuberculosis Research Center, Changwon 631-710, Republic of Korea \\ ${ }^{3}$ Mokpo National Hospital, Mokpo 530-828, Republic of Korea \\ ${ }^{4}$ Tuberculosis Research Section, Laboratory of Clinical Infectious Disease, National Institute of \\ Allergy and Infectious Diseases, National Institutes of Health, Bethesda, MD 20852, USA \\ ${ }^{5}$ The Genome Research Center for Respiratory Pathogens, Yonsei University College of Medicine, \\ Seoul 120-752, Republic of Korea
}

Rapid diagnosis of multidrug-resistant tuberculosis (MDR-TB) is essential for the prompt initiation of effective second-line therapy to improve treatment outcome and limit transmission of this obstinate disease. A variety of molecular methods that enable the rapid detection of mutations implicated in MDR-TB have been developed. The sensitivity of the methods is dependent, in principle, on the repertoire of mutations being detected, which is typically limited to mutations in the genes rpoB, katG and the promoter region of inhA. In this study, a new reverse hybridization assay, REBA MTB-MDR (M\&D), that probes mutations in the oxyR-ahpC intergenic region, in addition to those in $r p o B, k a t G$ and the inhA promoter region, was evaluated. A set of 240 Mycobacterium tuberculosis clinical isolates from patients receiving retreatment regimens was subjected to conventional phenotypic drug-susceptibility testing (DST) and the REBA MTB-MDR assay. The nucleotide sequences of the loci known to be involved in drug resistance were determined for comparison. In brief, the results showed that the REBA MTB-MDR assay efficiently recognized nucleotide changes in the oxy $R-a h p C$ intergenic region as well as those in rpo $B, k a t G$ and the inhA promoter region with higher sensitivity, resulting in an $81.0 \%$ detection rate for isoniazid resistance. Inclusion of the $\mathrm{xy} R-\mathrm{ahpC}$ intergenic region in the REBA MTB-MDR assay improved the overall sensitivity of molecular DST for MDR-TB from 73.1 to $79.9 \%$.

\section{INTRODUCTION}

The emergence of Mycobacterium tuberculosis strains resistant to at least isoniazid (INH) and rifampicin (RIF), the two most potent components of front-line antituberculosis (TB) therapy, termed multidrug-resistant TB (MDR-TB), is a serious cause for concern to TB control programmes worldwide. Development of MDR-TB significantly worsens the prognosis for achieving a durable cure, presages treatment failure and prolongs the period of transmission potential. Rapid diagnosis of MDR-TB,

Abbreviations: $\mathrm{Cl}$, confidence interval; DST, drug-susceptibility testing; $\mathrm{INH}$, isoniazid; MDR, multidrug resistant; MT, mutated; RIF, rifampicin; TB, tuberculosis; UPS, upstream promoter sequence; WT, wild-type. therefore, is essential for the prompt initiation of effective chemotherapy and the prevention of disease spread.

The development of drug resistance is the result of selection of random genetic mutations in genes associated with drug resistance. The mechanism of resistance to RIF involves missense mutations, small deletions or insertions in the $r p o B$ gene encoding the $\beta$-subunit of RNA polymerase. Studies from diverse countries have shown that 95-96\% of all RIFresistant isolates have mutations within an 81 bp 'core region' of rpoB (Bártfai et al., 2001; Cavusoglu et al., 2002; Herrera et al., 2003; Mani et al., 2001; Telenti et al., 1993; Yue et al., 2003). In contrast, but perhaps not unexpectedly given its highly complex mechanism of action, the mutations causing INH resistance are located in more than three genes and regions (Barry et al., 1998; Slayden \& Barry, 
2000). Depending on the sample set analysed, it has been reported that $50-95 \%$ of INH-resistant strains contain mutations in codon 315 of the kat $G$ gene encoding the catalase-peroxidase (Mokrousov et al., 2002; Musser et al., 1996; Piatek et al., 2000; Telenti et al., 1997) and 20-35\% harbour mutations in the inhA promoter region (Musser et al., 1996; Piatek et al., 2000; Telenti et al., 1997). Moreover, $10-15 \%$ of INH-resistant strains have mutations in the $\operatorname{oxy} R-a h p C$ intergenic region, although there is no direct evidence relating mutation at this region and INH resistance (Piatek et al., 2000; Telenti et al., 1997).

There has been an increasing interest in the development of rapid molecular methods for detection of those mutations associated with drug resistance to replace the conventional phenotypic drug-susceptibility testing (DST), which is based on culture and typically requires several months. PCR-based methods with readouts including line probe assays, analysis with DNA microarrays and real-time PCR have been the focus of much recent effort in developing molecular DST methods to determine resistance to RIF and INH (Cirillo et al., 2004; Edwards et al., 2001; El-Hajj et al., 2001; Herrera-León et al., 2005; van Doorn et al., 2003). Among the most successful of these molecular diagnostic methods is the GenoType MTBDRplus assay (Hain LifeScience), which is based on reverse hybridization of amplicons containing $r p o B, k a t G$ and inhA from test strains to probes carrying specific mutations in these genes. This DNA line probe assay performs well and offers substantial promise as a rapid molecular DST methodology (Hillemann et al., 2007; Mäkinen et al., 2006). This kit was designed to probe mutations only in the $k a t G$ gene and inhA promoter region in determining INH resistance; however, approximately $10-15 \%$ of INH-resistant $M$. tuberculosis strains have mutations in the oxyR-ahpC intergenic region with additional mutation of $k a t G$ outside codon 315 .

The aim of this study was to evaluate the impact of expanding the coverage of polymorphic alleles associated with drug resistance for the detection of MDR-TB using a new reverse hybridization assay, REBA MTB-MDR $(M \& D)$, that analyses the $o x y R-a h p C$ intergenic region in addition to rpoB, kat $G$ and the inh $A$ promoter region.

\section{METHODS}

M. tuberculosis clinical isolates and DST. The strains used in this study were obtained from National Masan Hospital or Yonsei University College of Medicine in South Korea. A total of $240 \mathrm{M}$. tuberculosis strains were isolated from $\mathrm{TB}$ patients receiving retreatment regimens for TB. DST of these isolates was performed by the absolute concentration method on Löwenstein-Jensen medium containing $0.2 \mu \mathrm{g} \mathrm{INH} \mathrm{ml} \mathrm{m}^{-1}$ or $40 \mu \mathrm{g}$ RIF $\mathrm{ml}^{-1}$, as described previously (American Thoracic Society \& Centers for Disease Control and Prevention, 2000).

Genomic DNA preparation. A loop of fresh M. tuberculosis culture on Löwenstein-Jensen medium was suspended in $400 \mu \mathrm{l}$ TE buffer [10 mM Tris/HCl ( $\mathrm{pH} \mathrm{8.0),} 1 \mathrm{mM}$ EDTA] in a screw-capped microcentrifuge tube. Following heating at $80{ }^{\circ} \mathrm{C}$ for $1 \mathrm{~h}$, the heat- killed bacteria were centrifuged at $13400 \mathrm{~g}$ for $5 \mathrm{~min}$, and $5 \mu \mathrm{l}$ of the supernatant was used for PCR amplification.

PCR amplification and sequencing of genes associated with drug resistance. A mixture of oligonucleotide primer sets specific to $r p o B, k a t G$, the inhA promoter region and the $\operatorname{oxy} R-a h p C$ intergenic region was supplied with the REBA MTB-MDR kit. Regions of $r p o B$, $k a t G$, the $i n h A$ promoter region and the $\operatorname{xxy} R-a h p C$ intergenic region were amplified by multiplex PCR using the REBA MTB-MDR primer mixture and the heat-killed bacterial supernatant, prepared as described above, according to the manufacturer's instructions. PCR products verified for the amplification of target DNA by agarose gel electrophoresis were subjected to DNA sequencing of both strands. The same PCR products were used for the reverse blot hybridization assay.

Reverse blot hybridization assay. The REBA MTB-MDR kit contains 13 probes detecting wild-type (WT) sequences and six probes recognizing mutated (MT) sequences for the determination of INH and RIF resistance, as well as one probe specific for $M$. tuberculosis (MTB; Table 1) and a mycobacterial genus-specific probe (Myc; Table 1). Hybridization of the PCR products with the probes immobilized on a membrane was carried out according to the manufacturer's instructions. Briefly, denatured PCR products in $2 \times$ SSPE (150 mM NaCl, $10 \mathrm{mM} \mathrm{NaH} \mathrm{PO}_{4}, 1 \mathrm{mM}$ EDTA)/0.1\% SDS were incubated with REBA MTB-MDR membrane strips at $50{ }^{\circ} \mathrm{C}$ on a Mini-Incubation Tray (Bio-Rad). Following washing with $2 \times$ SSPE $/ 0.5 \%$ SDS at $65{ }^{\circ} \mathrm{C}$, the strips were incubated with streptavidinconjugated alkaline phosphatase in $2 \times \mathrm{SSPE} / 0.5 \%$ SDS at ambient temperature, after which they were washed with $50 \mathrm{mM}$ Tris/ $\mathrm{HCl}$ ( $\mathrm{pH} 7.5) / 150 \mathrm{mM} \mathrm{NaCl}$. The hybridized amplicons carrying biotin incorporated into the PCR primers were detected by incubating the strips with nitro blue tetrazolium chloride and 5-bromo-4-chloro-3indolyl phosphate in $100 \mathrm{mM}$ Tris/HCl (pH 9.5)/100 mM NaCl/ $50 \mathrm{mM} \mathrm{MgCl} 2$. The presence of mutations was indicated either by lack of hybridization to the WT probes and hybridization to the corresponding MT probes, or simply by lack of hybridization to the respective WT probe. All experiments were performed in duplicate. The sensitivity of the REBA MTB-MDR assay was determined as the proportion of drug-resistant isolates identified by the assay compared with those determined to be resistant by phenotypic DST, whilst the specificity was determined as the proportion of drug-susceptible isolates identified by the assay compared with those determined by phenotypic DST. These calculations and the $95 \%$ confidence intervals (CIs) were computed using Prism 5 software (GraphPad).

\section{RESULTS}

\section{DST and reverse blot hybridization assay}

A total of 240 clinical isolates of $M$. tuberculosis from Korean patients undergoing retreatment for $\mathrm{TB}$ were included in this study. Of these isolates, 134 were resistant to both INH and RIF, 40 were resistant only to INH and two were RIF monoresistant, whilst 64 were susceptible to both INH and RIF as determined by phenotypic DST (Table 2). Genotypic analysis of RIF and INH resistance was carried out using the REBA MTB-MDR assay on all the clinical isolates. Fig. 1 shows an example of a typical analysis of six strains. Whilst drug-susceptible M. tuberculosis strain H37Rv clearly hybridized to all of the WT probes and none of the MT probes, other drug-resistant isolates gave unique hybridization patterns depending on 
Table 1. Probes used in the reverse blot hybridization assay

\begin{tabular}{|c|c|c|}
\hline Probe & Sequence $\left(5^{\prime} \rightarrow 3^{\prime}\right)$ & Description \\
\hline Myc & GACGTCGTCGCCACCATCGA & Mycobacterial probe \\
\hline MTB & AAACATGTCGGCGAGCCC & M. tuberculosis probe \\
\hline rрoв WT2 & ATGGACCAGAACAACCCG & rpoB codons $515-520 \mathrm{WT}$ \\
\hline rрoв WT3 & CCGCTGTCGGGGTTGACC & rpoB codons $521-525 \mathrm{WT}$ \\
\hline rрoв WT4 & TTGACCCACAAGCGCCGA & rpoB codons 524-529 WT \\
\hline rров MT1 & CTGTTGGCGCTGGGGC & rpoB codon $531(\mathrm{TCG} \longrightarrow \mathrm{TTG})$ \\
\hline rров МТ2 & AAATGTCGGCGCCGGGGCC & rpoB codon $533(\mathrm{CTG} \longrightarrow \mathrm{CCG})$ \\
\hline гров МТ3 & TTCATGTACCAGAACAACCCG & $r p o B$ codon $516(\mathrm{GAC} \rightarrow \mathrm{TAC})$ \\
\hline katG $315 \mathrm{WT}$ & CACCAGCGGCATCGAG & kat $G$ codon 315 AGC WT \\
\hline katG $315 \mathrm{MT}$ & ATCACCACCGGCATCGAG & $k a t G$ codon $315(\mathrm{AGC} \rightarrow \mathrm{ACC})$ \\
\hline inhA 15UPS WT & CGCGGCGAGACGATAGG & inhA UPS -15 WT \\
\hline $\operatorname{ahp} C \mathrm{WT} 2$ & CCTTTGCCTGACAGCGACTT & $\operatorname{ahpC}-38$ to $-18 \mathrm{WT}$ \\
\hline ahpC WT3 & CACGGCACGATGGAATGTC & $\operatorname{ahp} C-17$ to $+2 \mathrm{WT}$ \\
\hline ahpC WT4 & GCAACCAAATGCATTGTCCGC & $a h p C+3$ to $+23 \mathrm{WT}$ \\
\hline $\operatorname{ahpC~WT5}$ & TTTGATGATGAGGAGAGTCATGC & $a h p C+24$ to $+44 \mathrm{WT}$ \\
\hline
\end{tabular}

the mutations that they were carrying, shown by hybridization to the MT probes and lack of hybridization to the WT probes.

\section{Frequency of mutations associated with RIF resistance}

The REBA MTB-MDR assay was able to detect 132/136 RIF-resistant isolates (sensitivity 97\%; CI 90.8-98.9) and showed no mutations in the 104 RIF-susceptible isolates. These results were fully confirmed by DNA sequencing. The most frequent point mutation among the 136 RIFresistant isolates was observed at codon 531 of the rpoB gene (66 isolates, $48.5 \%$ ), with 64 isolates showing a $\mathrm{TCG} \rightarrow \mathrm{TTG}(\mathrm{Ser} \rightarrow$ Leu $)$ nucleotide transition. Two isolates lacking hybridization signals from the $r p o B$ WT5 probe were determined to have a TCG $\longrightarrow$ TGG (Trp) transversion by DNA sequencing. Other mutations were detected in alternative $r p o B$ codons including codon 526 (29 isolates, $21.3 \%$ ), codon 516 (23 isolates, $16.9 \%$ ), codons 513 and 533 (six isolates each, $4.4 \%$, respectively), codon 511 (three isolates, $2.2 \%$ ), codons 517 and 522 (two isolates each, $1.5 \%$, respectively) and codons 510, 512, 515, 523 and 540 (one isolate each, $0.7 \%$, respectively). A CCA deletion overlapping codons 516 and 517 was observed in one isolate $(0.7 \%)$. Among these isolates with confirmed mutations, double mutations were detected in 11 isolates. Four isolates were found not having any mutation in $r p o B$. No mutation in the $r p o B$ gene was detected in any of the 104 RIF-susceptible isolates. These mutations were all identified either by a signal from the specific MT probe and lack of the corresponding WT signal, or by lack of hybridization to the respective WT probe (Table 2). Overall, 14 different hybridization patterns representing 31 different mutation patterns in the $r p o B$ gene were observed.

\section{Frequency of mutations associated with INH resistance}

Among the 174 INH-resistant isolates, the REBA MTBMDR assay detected mutations in at least one of the resistance-associated regions, $k a t G$, the inhA promoter and the $o x y R-a h p C$ intergenic region, in a total of 141 strains (81.0\% sensitivity, CI 74.4-86.6) and these results were confirmed by DNA sequencing. By far the majority of these were detected in the $k a t G$ gene with a mutation in codon 315, AGC $\rightarrow$ ACC (Ser $\rightarrow$ Thr), accounting for $51.1 \%$ (89 isolates), and a mutation in codon 315 to AAC (Asn) representing $2.3 \%$ (four isolates). The second most common site of mutation was in the upstream promoter sequence (UPS) of inhA, accounting for $26.4 \%$ (46 isolates). Forty-one isolates $(23.6 \%)$ carried a $\mathrm{C} \rightarrow \mathrm{T}$ transition at the -15 position, and four isolates $(2.3 \%)$ carried a $\mathrm{T} \rightarrow \mathrm{C}$ mutation and one isolate $(0.6 \%)$ carried a $\mathrm{T} \rightarrow \mathrm{A}$ mutation at the -8 position. Seventeen isolates $(9.8 \%)$ carried mutations in the oxyR-ahpC intergenic region, and one of them had a double mutation in this region. Among these isolates, eight (4.6\%) had mutations in both $k a t G$ at codon 315 and the inhA promoter region. Three isolates $(1.7 \%)$ had mutations at kat $G$ codon 315 and in the $o x y R-a h p C$ intergenic region, whilst four isolates $(2.3 \%)$ had mutations in the inhA promoter region and $\operatorname{oxyR}-a h p C$ intergenic regions. Mutations solely in the 
Table 2. Hybridization patterns of $M$. tuberculosis clinical isolates by the REBA MTB-MDR assay

+ and - indicate presence and absence of the hybridization signal to the probes, respectively.

\begin{tabular}{|c|c|c|c|c|c|c|c|c|c|c|c|c|c|c|c|c|c|c|c|c|c|}
\hline \multirow{2}{*}{$\begin{array}{l}\text { Phenotypic } \\
\text { DST } \\
\text { (no. of } \\
\text { isolates) }^{\star}\end{array}$} & \multicolumn{8}{|c|}{ rpoB } & \multicolumn{2}{|c|}{ katG 315} & \multicolumn{2}{|c|}{$\begin{array}{c}\text { inhA } \\
\text { 15UPS }\end{array}$} & \multicolumn{2}{|c|}{ inhA 8UPS } & \multicolumn{5}{|c|}{$\operatorname{ahpC}$} & \multirow{2}{*}{$\begin{array}{l}\text { No. of } \\
\text { isolates }\end{array}$} & \multirow{2}{*}{$\begin{array}{c}\text { Interpretation } \\
\text { (no. of } \\
\text { isolates) }\end{array}$} \\
\hline & WT1 & WT2 & WT3 & WT4 & WT5 & MT1 & MT2 & MT3 & WT & MT & WT & MT & WT & MT & WT1 & WT2 & WT3 & WT4 & WT5 & & \\
\hline \multirow{31}{*}{$\begin{array}{l}\mathrm{RIF}^{\mathrm{R}} \mathrm{INH}^{\mathrm{R}} \\
(134)\end{array}$} & + & + & + & + & - & + & - & - & - & + & + & - & + & - & + & + & + & + & + & 27 & rpoB katG (62) \\
\hline & + & + & + & + & - & - & + & - & - & + & + & - & + & - & + & + & + & + & + & 3 & \\
\hline & + & + & + & + & - & - & + & - & - & - & + & - & + & - & + & + & + & + & + & 1 & \\
\hline & + & + & + & + & - & - & - & - & - & + & + & - & + & - & + & + & + & + & + & 1 & \\
\hline & + & + & + & - & + & - & - & - & - & + & + & - & + & - & + & + & + & + & + & 10 & \\
\hline & + & + & + & - & + & - & - & - & - & - & + & - & + & - & + & + & + & + & + & 1 & \\
\hline & + & - & + & + & + & - & - & + & - & + & + & - & + & - & + & + & + & + & + & 5 & \\
\hline & + & - & + & + & + & - & - & - & - & + & + & - & + & - & + & + & + & + & + & 10 & \\
\hline & + & - & + & + & + & - & - & - & - & - & + & - & + & - & + & + & + & + & + & 1 & \\
\hline & - & + & + & + & + & - & - & - & - & + & + & - & + & - & + & + & + & + & + & 2 & \\
\hline & + & - & + & + & - & - & + & - & - & + & + & - & + & - & + & + & + & + & + & 1 & \\
\hline & + & + & + & + & - & + & - & - & + & - & - & + & + & - & + & + & + & + & + & 15 & rpoB inhA (25) \\
\hline & + & + & + & - & + & - & - & - & + & - & - & + & + & - & + & + & + & + & + & 5 & \\
\hline & + & - & + & + & + & - & - & + & + & - & - & + & + & - & + & + & + & + & + & 1 & \\
\hline & - & + & + & + & + & - & - & - & + & - & - & + & + & - & + & + & + & + & + & 2 & \\
\hline & - & + & - & + & + & - & - & - & + & - & - & + & + & - & + & + & + & + & + & 1 & \\
\hline & + & + & + & + & - & + & - & - & + & - & + & - & - & + & + & + & + & + & + & 1 & \\
\hline & + & + & + & + & - & + & - & - & + & - & + & - & + & - & - & + & + & + & + & 1 & rpoB ahpC (9) \\
\hline & + & + & + & + & - & + & - & - & + & - & + & - & + & - & + & + & - & + & + & 2 & \\
\hline & + & + & + & - & + & - & - & - & + & - & + & - & + & - & + & + & - & + & + & 2 & \\
\hline & + & + & + & - & + & - & - & - & + & - & + & - & + & - & + & - & + & + & + & 1 & \\
\hline & + & + & - & + & + & - & - & - & + & - & + & - & + & - & + & + & - & + & + & 1 & \\
\hline & + & + & - & + & + & - & - & - & + & - & + & - & + & - & - & + & + & + & + & 1 & \\
\hline & - & + & + & - & + & - & - & - & + & - & + & - & + & - & + & + & - & + & + & 1 & \\
\hline & + & + & + & + & - & + & - & - & - & + & - & + & + & - & + & + & + & + & + & 3 & $\begin{array}{c}\text { rpoB katG } \\
\text { inhA (7) }\end{array}$ \\
\hline & + & + & + & - & + & - & - & - & - & + & - & + & + & - & + & + & + & + & + & 1 & \\
\hline & + & - & + & + & + & - & - & - & - & + & + & - & - & + & + & + & + & + & + & 1 & \\
\hline & - & - & + & + & + & - & - & - & - & + & + & - & - & - & + & + & + & + & + & 1 & \\
\hline & + & + & + & + & - & - & + & - & - & - & + & - & - & + & + & + & + & + & + & 1 & \\
\hline & + & + & + & + & - & + & - & - & - & + & + & - & + & - & - & + & + & + & + & 1 & 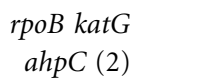 \\
\hline & - & + & + & - & + & - & - & - & - & + & + & - & + & - & + & + & - & + & + & 1 & \\
\hline
\end{tabular}


Table 2. cont.

\begin{tabular}{|c|c|c|c|c|c|c|c|c|c|c|c|c|c|c|c|c|c|c|c|c|c|}
\hline $\begin{array}{l}\text { Phenotypic } \\
\text { DST } \\
\text { (no. of } \\
\text { isolates)* }\end{array}$ & \multicolumn{8}{|c|}{$r p o B$} & \multicolumn{2}{|c|}{ katG 315} & \multicolumn{2}{|c|}{$\begin{array}{l}\text { inhA } \\
\text { 15UPS }\end{array}$} & \multicolumn{2}{|c|}{ inhA 8UPS } & \multicolumn{5}{|c|}{$\operatorname{ahpC}$} & $\begin{array}{l}\text { No. of } \\
\text { isolates }\end{array}$ & $\begin{array}{l}\text { Interpretation } \\
\text { (no. of } \\
\text { isolates) }\end{array}$ \\
\hline \multirow[b]{9}{*}{$\mathrm{INH}^{\mathrm{R}}(40)$} & + & + & + & + & - & + & - & - & + & - & + & - & - & + & + & + & - & + & + & 1 & 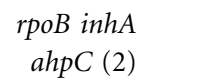 \\
\hline & + & - & + & - & + & - & - & - & + & - & - & + & + & - & + & + & - & + & + & 1 & \\
\hline & + & - & + & + & + & - & - & - & + & - & + & - & + & - & + & + & + & + & + & 4 & \\
\hline & - & + & + & + & + & - & - & - & + & - & + & - & + & - & + & + & + & + & + & 2 & \\
\hline & + & + & + & + & + & - & - & - & - & + & + & - & + & - & + & + & + & + & + & 1 & katG (1) \\
\hline & + & + & + & + & + & - & - & - & + & - & + & + & + & - & + & + & + & + & + & 1 & $\operatorname{inh} A(1)$ \\
\hline & + & + & + & + & + & - & - & - & - & + & - & + & + & - & + & + & + & + & + & 1 & katG inhA (1) \\
\hline & + & + & + & + & + & - & - & - & + & - & + & - & + & - & + & + & + & + & + & 1 & No mutation (1) \\
\hline & + & + & + & + & + & - & - & - & - & + & + & - & + & - & + & + & + & + & + & 20 & katG (20) \\
\hline $\mathrm{RIF}^{\mathrm{S}} \mathrm{INH}^{\mathrm{S}}(64)$ & + & + & + & + & + & - & - & - & + & - & + & - & + & - & + & + & + & + & + & 64 & No mutation (64) \\
\hline Total & & & & & & & & & & & & & & & & & & & & 240 & \\
\hline
\end{tabular}

${ }^{\star} \mathrm{R}$, Resistant; $\mathrm{S}$, sensitive. 


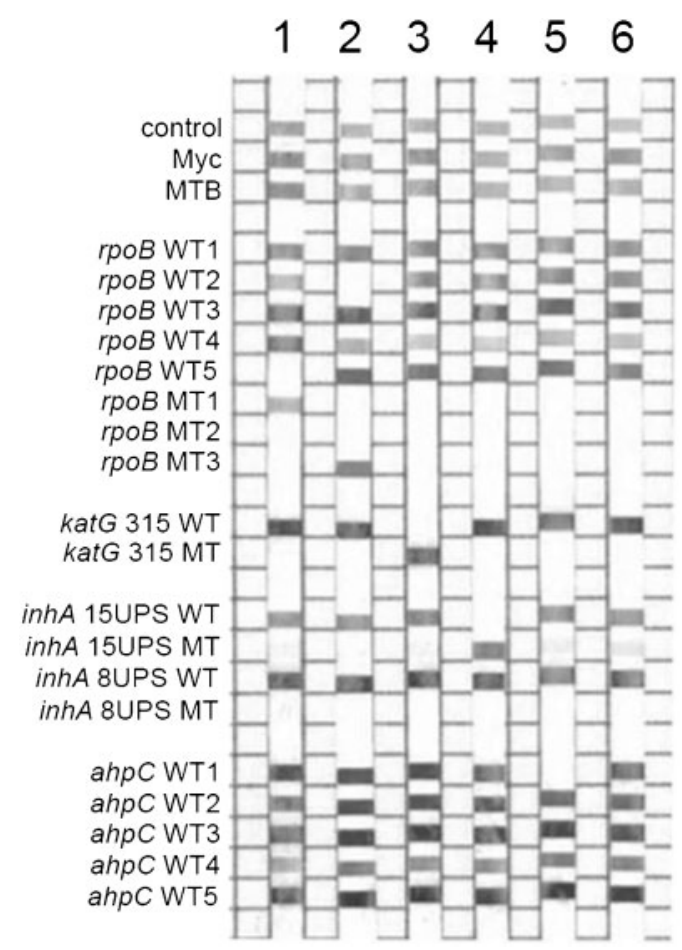

Fig. 1. Hybridization patterns of $M$. tuberculosis strains by the REBA MTB-MDR assay. The probes immobilized on the strip are indicated on the left. Lanes: 1 , clinical isolate carrying an rpo $B$ mutation at codon 531 (TCG $\rightarrow$ TTG); 2, clinical isolate carrying an $r p o B$ mutation at codon $516(\mathrm{GAC} \longrightarrow \mathrm{TAC}) ; 3$, clinical isolate carrying a kat $G$ mutation at codon $315(A G C \longrightarrow A C C)$; 4, clinical isolate carrying a mutation in the upstream promoter sequence (UPS) of inhA at the -15 position $(\mathrm{C} \rightarrow \mathrm{T})$; 5 , clinical isolate carrying a mutation in the $x y R-a h p C$ intergenic region at the -39 position $(\mathrm{C} \rightarrow \mathrm{T})$; 6, M. tuberculosis strain H37Rv.

oxyR-ahpC intergenic region were observed in ten isolates $(5.8 \%)$. There were 33 INH-resistant isolates (19.0\%) without any observed mutations in these loci. The 66 INHsusceptible isolates did not carry any mutations in these three regions.

These results could be visualized directly by the dual signal changes, loss of the WT probe signal and appearance of the MT probe signal, or only by loss of the WT probe signal, in all but two cases. One isolate had a $\mathrm{C} \rightarrow \mathrm{T}$ change at the -30 position and both WT (C) and MT (T) sequences at the +2 position in the $o x y R-a h p C$ intergenic region, as confirmed by DNA sequencing, suggesting a possible mixed infection. This isolate was determined to be INHresistant by the REBA MTB-MDR assay because the $\mathrm{C} \rightarrow \mathrm{T}$ change at the -30 position was detected by a lack of hybridization signal of the $\operatorname{ahpC} \mathrm{WT} 2$ probe, whilst the ahpC WT3 probe still gave the WT pattern. The other isolate also appeared to be a mixed-infection case that had WT (C) and MT (T) sequences simultaneously at the -10 position in the oxyR-ahpC intergenic region. Although this isolate gave a WT pattern by the REBA MTB-MDR assay for the $a h p C$ WT3 probe, this isolate was still detected as resistant to INH by the REBA MTB-MDR assay, as it also had mutation in the inhA promoter region. Overall, 17 different hybridization patterns representing 22 different mutations at codon 315 of $k a t G$, in the inhA promoter region and in the $o x y R-a h p C$ intergenic region were observed.

\section{Sensitivity and specificity of REBA MTB-MDR results}

As shown in Table 2, the REBA MTB-MDR assay correctly identified 107/134 MDR isolates, resulting in an overall sensitivity of $79.8 \%$ (CI 71.8-86.1). Likewise, no mutations in the four gene regions analysed were detected by the REBA MTB-MDR assay among the 64 RIF- and INHsusceptible isolates, resulting in a specificity of $100 \%$. As already alluded to above, in almost all isolates, the phenotypic DST patterns could be predicted by the REBA MTB-MDR assay. The strains that had double mutations in the same gene, and also showed mutations in other INH resistance-associated regions, were still detected as MDR by the REBA MTB-MDR assay. In total, 44 different hybridization patterns representing 59 different mutations in the $r p o B$ hot-spot region, codon 315 of kat $G$, the inhA promoter region and the $o x y R-a h p C$ intergenic region of $107 \mathrm{MDR}$ isolates were detected (Table 2).

\section{DISCUSSION}

In this study, we evaluated the utility of incorporating additional putative resistance-related mutations into a REBA MTB-MDR assay using a panel of $240 \mathrm{M}$. tuberculosis clinical isolates, of which 134 were MDR. This assay contains both WT and MT probes in the $81 \mathrm{bp}$ hot-spot region of the $r p o B$ gene, probes for codon 315 of the kat $G$ gene, probes for the -15 or -8 UPS of the inhA promoter region and $\mathrm{WT}$ probes of the intergenic region of the $o x y R-a h p C$ gene immobilized on a membrane. The presence of mutations was indicated either by lack of hybridization to the WT oligonucleotide probes and hybridization to the corresponding mutant oligonucleotide probes, or by lack of hybridization to the respective WT sequence only.

This assay successfully detected 107/134 MDR isolates including nine MDR isolates with mutations in the rpoB gene and the oxyR-ahpC intergenic region but not in the $k a t G$ or $i n h A$ genes. These nine MDR isolates would have been missed by use of previous methods that do not assess for the presence of mutations in the $o x y R-a h p C$ intergenic region. The additional isolates correctly detected amounted to a $5.7 \%$ increase in the INH resistance detection rate from 75.3 to $81.0 \%$, and a $6.8 \%$ increase in the MDR-TB detection rate from 73.1 to $79.9 \%$. This increase in the detection rate was achieved by the REBA MTB-MDR assay due to the inclusion of probes spanning 
the $\operatorname{oxyR}-a h p C$ intergenic region. Compared with the data from phenotypic DST for these strains, the sensitivity and specificity of the REBA MTB-MDR assay were determined to be 79.9 and $100 \%$, respectively. It has been reported previously that $10-15 \%$ of INH-resistant strains have mutations in the oxyR-ahpC intergenic region with inactivation of KatG (Piatek et al., 2000; Telenti et al., 1997). The relationship between INH resistance and mutations of the $\operatorname{oxy} R-a h p C$ intergenic region is not yet clearly understood. Therefore, future studies of the ten INH-resistant strains containing mutations only in the $o x y R-a h p C$ intergenic region will be needed to determine their precise MICs and to investigate whether they have additional mutations of the $k a t G$ gene outside codon 315 . This future study will give more information about the relationship with INH resistance and mutations in the $o x y R-a h p C$ intergenic region.

Signals for both WT and MT probes, suggestive of mixed infection with two distinct strains, one WT and the other a MT strain, were detected in several cases. These isolates had another mutation in the same region and had mutations in other INH resistance-associated regions, and were therefore determined to be MDR by the REBA MTB-MDR assay. Although it is not easy to make a simple recommendation in such cases of mixed infection with resistant and susceptible M. tuberculosis strains as observed in this study, or in mixed infections containing $M$. tuberculosis and a non-tuberculous mycobacterium (Hillemann et al., 2007), we favour a conservative approach of reporting such strains as likely to be resistant after exclusion of involvement of a non-tuberculous mycobacterium.

The REBA MTB-MDR assay was able to detect 132/136 RIF-resistant isolates and showed no mutations in the 104 RIF-susceptible isolates, and these results were fully confirmed by conventional DNA sequencing. In general, mutations in the $r p o B$ gene account for $95-96 \%$ of RIFresistant M. tuberculosis strains worldwide (Musser, 1995; Raviglione et al., 1995). Similarly, the REBA MTB-MDR assay correctly detected 141 INH-resistant isolates out of 174 isolates $(81 \%)$ determined to be drug resistant by phenotypic DST, whilst not finding any polymorphisms in $66 \mathrm{INH}$-susceptible isolates.

In addition to the mixed-infection cases, reverse line blotting assays will continue to underestimate the true number of resistant strains because of limitations of knowledge regarding the genotypic markers of drug resistance. In this study, we showed that inclusion of a relatively modest number of additional probes to detect additional mutations associated with INH resistance in the oxy $R-a h p C$ intergenic region improved the detection rate of drug-resistant $\mathrm{TB}$ in this patient population from 73.1 to $79.9 \%$, which is an improvement over previously implemented line probe assays. This assay is being evaluated on clinical specimens to determine its potential for improving rapid diagnosis of MDR-TB in a prospective clinical trial.

\section{ACKNOWLEDGEMENTS}

This work was supported by the Intramural Research Program of the National Institutes of Health, National Institute of Allergy and Infectious Disease.

\section{REFERENCES}

American Thoracic Society \& Centers for Disease Control and Prevention (2000). Diagnostic standards and classification of tuberculosis in adults and children. Am J Respir Crit Care Med 161, 1376-1395.

Barry, C. E., III, Slayden, R. A. \& Mdluli, K. (1998). Mechanisms of isoniazid resistance in Mycobacterium tuberculosis. Drug Resist Updat $1,128-134$.

Bártfai, Z., Somoskövi, A., Ködmön, C., Szabó, N., Puskás, E., Kosztolányi, L., Faragó, E., Mester, J., Parsons, L. M. \& Salfinger, M. (2001). Molecular characterization of rifampin-resistant isolates of Mycobacterium tuberculosis from Hungary by DNA sequencing and the line probe assay. J Clin Microbiol 39, 3736-3739.

Cavusoglu, C., Hilmioglu, S., Guneri, S. \& Bilgic, A. (2002). Characterization of $r p o B$ mutations in rifampin-resistant clinical isolates of Mycobacterium tuberculosis from Turkey by DNA sequencing and line probe assay. J Clin Microbiol 40, 4435-4438.

Cirillo, D. M., Piana, F., Frisicale, L., Quaranta, M., Riccabone, A., Penati, V., Vaccarino, P. \& Marchiaro, G. (2004). Direct rapid diagnosis of rifampicin-resistant $M$. tuberculosis infection in clinical samples by line probe assay (INNO LiPA Rif-TB). New Microbiol 27, 221-227.

Edwards, K. J., Metherell, L. A., Yates, M. \& Saunders, N. A. (2001). Detection of rpoB mutations in Mycobacterium tuberculosis by biprobe analysis. J Clin Microbiol 39, 3350-3352.

El-Hajj, H. H., Marras, S. A., Tyagi, S., Kramer, F. R. \& Alland, D. (2001). Detection of rifampin resistance in Mycobacterium tuberculosis in a single tube with molecular beacons. J Clin Microbiol 39, 4131-4137.

Herrera, L., Jiménez, S., Valverde, A., García-Aranda, M. A. \& SáezNieto, J. A. (2003). Molecular analysis of rifampicin-resistant Mycobacterium tuberculosis isolated in Spain (1996-2001). Description of new mutations in the rpoB gene and review of the literature. Int J Antimicrob Agents 21, 403-408.

Herrera-León, L., Molina, T., Saíz, P., Sáez-Nieto, J. A. \& Jiménez, M. S. (2005). New multiplex PCR for rapid detection of isoniazid-resistant Mycobacterium tuberculosis clinical isolates. Antimicrob Agents Chemother 49, 144-147.

Hillemann, D., Rüsch-Gerdes, S. \& Richter, E. (2007). Evaluation of the GenoType MTBDRplus assay for rifampin and isoniazid susceptibility testing of Mycobacterium tuberculosis strains and clinical specimens. J Clin Microbiol 45, 2635-2640.

Mäkinen, J., Marttila, H. J., Marjamäki, M., Viljanen, M. K. \& Soini, H. (2006). Comparison of two commercially available DNA line probe assays for detection of multidrug-resistant Mycobacterium tuberculosis. J Clin Microbiol 44, 350-352.

Mani, C., Selvakumar, N., Narayanan, S. \& Narayanan, P. R. (2001). Mutations in the rpoB gene of multidrug-resistant Mycobacterium tuberculosis clinical isolates from India. J Clin Microbiol 39, 2987-2990.

Mokrousov, I., Narvskaya, O., Otten, T., Limeschenko, E., Steklova, L. \& Vyshnevskiy, B. (2002). High prevalence of KatG Ser315Thr substitution among isoniazid-resistant Mycobacterium tuberculosis clinical isolates from northwestern Russia, 1996 to 2001. Antimicrob Agents Chemother 46, 1417-1424.

Musser, J. M. (1995). Antimicrobial agent resistance in mycobacteria: molecular genetic insights. Clin Microbiol Rev 8, 496-514. 
Musser, J. M., Kapur, V., Williams, D. L., Kreiswirth, B. N., van Soolingen, D. \& van Embden, J. D. (1996). Characterization of the catalase-peroxidase gene $(k a t G)$ and inhA locus in isoniazid-resistant and -susceptible strains of Mycobacterium tuberculosis by automated DNA sequencing: restricted array of mutations associated with drug resistance. J Infect Dis 173, 196-202.

Piatek, A. S., Telenti, A., Murray, M. R., El-Hajj, H., Jacobs, W. R., Jr, Kramer, F. R. \& Alland, D. (2000). Genotypic analysis of Mycobacterium tuberculosis in two distinct populations using molecular beacons: implications for rapid susceptibility testing. Antimicrob Agents Chemother 44, 103-110.

Raviglione, M. C., Snider, D. E., Jr \& Kochi, A. (1995). Global epidemiology of tuberculosis. Morbidity and mortality of a worldwide epidemic. JAMA 273, 220-226.

Slayden, R. A. \& Barry, C. E., III (2000). The genetics and biochemistry of isoniazid resistance in Mycobacterium tuberculosis. Microbes Infect 2, 659-669.
Telenti, A., Imboden, P., Marchesi, F., Matter, L., Schopfer, K., Bodmer, T., Lowrie, D., Colston, M. J. \& Cole, S. (1993). Detection of rifampicin-resistance mutations in Mycobacterium tuberculosis. Lancet 341, 647-651.

Telenti, A., Honoré, N., Bernasconi, C., March, J., Ortega, A., Heym, B., Takiff, H. E. \& Cole, S. T. (1997). Genotypic assessment of isoniazid and rifampin resistance in Mycobacterium tuberculosis: a blind study at reference laboratory level. J Clin Microbiol 35, 719-723.

van Doorn, H. R., Claas, E. C., Templeton, K. E., van der Zanden, A. G., te Koppele Vije, A., de Jong, M. D., Dankert, J. \& Kuijper, E. J. (2003). Detection of a point mutation associated with high-level isoniazid resistance in Mycobacterium tuberculosis by using real-time PCR technology with $3^{\prime}$-minor groove binder-DNA probes. J Clin Microbiol 41, 4630-4635.

Yue, J., Shi, W., Xie, J., Li, Y., Zeng, E. \& Wang, H. (2003). Mutations in the $r p o B$ gene of multidrug-resistant Mycobacterium tuberculosis isolates from China. J Clin Microbiol 41, 2209-2212. 